\title{
Comparative anti-inflammatory and lipid- normalizing effects of metformin and omega-3 fatty acids through modulation of transcription factors in diabetic rats
}

\author{
Abhijit Ghadge ${ }^{1}$, Abhay Harsulkar ${ }^{1}$, Manjiri Karandikar², Vijaya Pandit ${ }^{3}$ and Aniket Kuvalekar ${ }^{{ }^{*}}$
}

\begin{abstract}
Background: Emerging evidence suggests beneficial effects of omega-3 fatty acids on diabetic complications. The present study compared the progressive effects of metformin and flax/fish oil on lipid metabolism, inflammatory markers, and liver and renal function test markers in streptozotocin-nicotinamide-induced diabetic rats.

Methods: Streptozotocin-induced diabetic rats were randomized into control and four diabetic groups: streptozotocin (STZ), metformin (200 mg/kg body weight (b.w)/day (D)), flax and fish oil (500 mg/kg b.w/D).

Results: Metformin and flax and fish oil exhibited increased expression of transcription factor peroxisome proliferator-activated receptor $\gamma$ while the treatment downregulated sterol regulatory element-binding protein 1 and nuclear factor $k \beta$ as compared to those of the STZ group. Apart from modulation of transcription factor expression, the expression of fatty acid synthase, long chain acyl CoA synthase, and malonyl-CoA-acyl carrier protein transacylase was lowered by flax/fish oil treatment. Serum cholesterol, triglycerides, and VLDL were also significantly reduced in the treatment groups as compared to those in the STZ group. Although pathological abnormalities were seen in the liver and kidneys of rats on metformin, no significant changes in liver/renal function markers were observed at day 15 and day 30 of the treatment groups. Flax/fish oil had protective effects toward pathological abnormalities in the liver and kidney. Flax/fish oil improved lipid profile and alkaline phosphatase at day 30 as compared to that at day 15 .

Conclusions: The present study demonstrates potential beneficial effects of metformin and flax/fish oil intervention in improving serum lipid profile by regulating the expression of transcription factors and genes involved in lipid metabolism in diabetic rats. In addition, these interventions also lowered the expression of atherogenic cytokines. The protective effects of flax/fish oil are worth investigating in human subjects on metformin monotherapy.
\end{abstract}

Keywords: Fish oil, Flax oil, Metformin, Omega-3 fatty acids, Streptozotocin

\section{Background}

Omega-3 polyunsaturated fatty acids (n-3 PUFA) constitute a fundamental part of cell membranes and exhibit a diverse range of membrane functions including functioning of transporters, signal transduction pathways, and gene expression (Liu and Ma 2014; Ander et al. 2003). Alpha-linolenic acid (ALA; 18:3 n-3) is a short

\footnotetext{
* Correspondence: kuaniket@gmail.com

${ }^{1}$ Nutrigenomics and Functional Foods Laboratory, Interactive Research School for Health Affairs (IRSHA), Bharati Vidyapeeth Deemed University, Pune-Satara Road, Pune, Maharashtra 411043, India

Full list of author information is available at the end of the article
}

chain n-3 PUFA obtained from flaxseed (a plant-derived food item) (Dessì et al. 2013; Mozaffarian and Wu 2012; Connor 2000) while eicosapentaenoic acid (EPA) and docosahexaenoic acid (DHA; 22:6 n-3) are the long chain n-3 PUFA derived from a seafood source, fish oil (Swanson et al. 2012). There is strong scientific evidence demonstrating anti-inflammatory, anti-atherogenic, vasodilatory, and lipid-lowering properties of n-3 PUFA (Jangale et al. 2013; Mozaffarian and Wu 2012; Connor 2000) due to which they have been implicated in some chronic diseases like cardiovascular disease (Ander et al. 2003), diabetes (Wu et al. 2012), and autoimmune diseases 
(Calder 2007). In view of this, dietary n-3 PUFA are considered as significant nutrients involved in metabolic regulation. There is a recent surge in research on effects of functional foods, like n-3 PUFA for the management of type 2 diabetes mellitus (T2DM).

Diabetes consists of a group of metabolic disorders involving distinct pathogenic mechanisms with hyperglycemia, arising due to impaired metabolism of glucose, lipids, and proteins (Prabhakar et al. 2013). T2DM is frequently associated with abnormal lipid profile (Ozder 2014) with perturbations in the lipid metabolism affected by abnormalities in the expression of hepatic transcription factors and genes (Erejuwa et al. 2012). Moreover, diabetics are more prone to develop chronic complications related to cardiovascular, renal (Forbes and Cooper 2013), and peripheral vascular tissues (King 2008).

Several oral hypoglycemic drugs such as biguanides, sulfonylurea, and thiazolidenediones are commonly used for the treatment of T2DM. Metformin is an old and widely used first-line agent, known for its anti-hyperglycemic properties, and is also reported to improve lipid profile, fat redistribution (Rojas and Gomes 2013), and chronic liver diseases (Zheng et al. 2015) and lower microvascular and macrovascular complications associated with T2DM (Kooy et al. 2009). Though it has rarely been reported to induce hepatocellular and cholestatic hepatic injury (Saadi et al. 2013) and hepatotoxicity (Miralles-Linares et al. 2012), there are very few reports examining its long-term effects for the management of T2DM.

Some investigations have evaluated the individual effects of metformin (Wang et al. 2014) or n-3 PUFA on the regulation of lipid metabolism genes in diabetes (Devarshi et al. 2013). The lipid-lowering actions of n-3 PUFA are attributed to the regulation of key transcription factors like peroxisome proliferator-activated receptors (PPAR) and sterol regulatory element-binding protein (SREBP), that control hepatic lipid metabolism (Di Minno et al. 2012). However, there are some conflicting results stating that supplementation with fish oil does not delay the onset of diabetes in rats at 12 months of age (Cummings et al. 2010) while other reports state that $\mathrm{n}-3$ PUFA slows the progression of T2DM and its complications (Nettleton and Katz 2005). However, there is lack of evidence for these effects of n-3 PUFA in T2DM and the underlying molecular mechanisms have not been well evaluated (Devarshi et al. 2013; Wu et al. 2012). A review by Hendrich points a need to carry out high-quality studies to assess the effects of ALA (Hendrich 2010). The above reports suggest the need for a meticulous evaluation of effects of ALA, EPA, and DHA on lipid metabolism and its underlying mechanism.

It is well known that streptozotocin (STZ) has a selective cytotoxic action on $\beta$-cells in the islets of Langerhans whereas nicotinamide has a partial protective role on $\beta$ - cells against STZ (Szkudelski 2012) and is commonly used for induction of type 2 diabetes mellitus in experimental animals (Devarshi et al. 2013; Pari and Saravanan 2007; Saravanan and Pari 2007; Brenna et al. 2003). Additionally, STZ-nicotinamide is considered as a suitable T2DM model to study the effects of metformin as well as herbal (Maheshwari et al. 2014; Sharma et al. 2012; Mohammadi et al. 2012; Li et al. 2011) and nutritional (Devarshi et al. 2013; Jangale et al. 2013) interventions as indicated by several animal studies. We selected peripheral blood mononuclear cells (PBMCs) to study gene expression profile since the blood is the most accessible tissue in humans, and as the profile of multiple tissues is shared with PBMCs, they reflect important metabolic changes in the liver (Konieczna et al. 2014). However, there are no reports examining the temporal effects of metformin and flax/fish oil diets on the lipid metabolism and biochemical markers in T2DM. Moreover, potential of these treatments to affect duration of the disease is poorly understood.

We hypothesized that metformin and omega-3 fatty acids could improve lipid metabolism and inflammatory cytokines by modulating the expression of transcription factors in STZ-nicotinamide-induced diabetic rats. The objectives of the present study were to examine the comparative effects of metformin and omega-3 fatty acids on serum lipid profile, expression of transcription factors and genes involved in lipid metabolism, and inflammation in STZ-nicotinamide-induced diabetic rats. Additionally, the progressive effects of these treatments on liver/renal function test markers and histological changes in these tissues were evaluated. We also compared the effects of these treatments on the above parameters at post treatment day 15 (D15) and day 30 (D30) to study their effects on the duration of disease.

\section{Methods \\ Chemicals and reagents}

Flax oil (Alvel-500) capsules were purchased from Real World Nutritional Laboratory (Pune, India) that contained $50 \%$ alpha-linolenic acid (ALA), $20 \%$ oleic acid, and $12 \%$ linoleic acid. Fish oil capsules (Maxepa) were purchased from Merck Limited (Goa, India) which contained $60 \% \mathrm{EPA}$ and $40 \%$ DHA. Streptozotocin (STZ), nicotinamide (Sigma Life Sciences, USA), and metformin (Glycomet $250 \mathrm{mg}$; USV Limited) were purchased from a local pharmacy.

\section{Experimental animals}

The study was carried out as per the CPCSEA (Committee for the Purpose of Control and Supervision of Experiments on Animals) guidelines after the approval of Institutional Animal Ethics Committee (Ref. No: BVDUMC/189/2014- 
2015). The male albino Wistar rats weighing between 150 and $200 \mathrm{~g}$ were procured from the institutional animal house and maintained under standard conditions throughout the experimentation (temperature $25 \pm 2{ }^{\circ} \mathrm{C}$, 12-h light:12-h dark cycle). Animals were fed with standard pellet diet (Nutrivet life science, Pune, M.S., India), and water was supplied ad libitum.

\section{Diabetes induction}

Animals were randomly assigned to five groups $(n=6)$. Diabetes was induced by administration of nicotinamide (110 $\mathrm{mg} / \mathrm{kg}$ body weight) in saline through intraperitoneal (i.p) injection. After $15 \mathrm{~min}$, STZ was administered ( $65 \mathrm{mg} / \mathrm{kg}$ body weight i.p) in sodium citrate buffer, $\mathrm{pH}$ 4.0. The fasting blood glucose levels of the rats were estimated after $48 \mathrm{~h}$ and on day 7 of STZ injection. Stable hyperglycemia was confirmed by elevated fasting blood glucose levels on day 7 after STZ injection. Animals with fasting blood glucose levels above $200 \mathrm{mg} / \mathrm{dl}$ were considered as diabetic and used for the study. After development of stable hyperglycemia, metformin or flax/fish oil treatment was given for 30 days. The dose of flax and fish oil was based on the earlier study carried out in our laboratory (Chavan et al. 2013). The study protocol is given in Fig. 1. Animals were randomly assigned to one of the following groups: group I: control group $(n=6)$ : received feed and water normally throughout the experiment; group II: STZ-induced diabetic group $(n=6)$ : administered nicotinamide $(110 \mathrm{mg} / \mathrm{kg}$ body weight) and STZ (65 mg/kg body weight) i.p single dose; group III: metformin group $(n=6)$ : administered metformin $(200 \mathrm{mg} / \mathrm{kg}$, body weight/D p.o); group IV: flax oil group $(n=6)$ : administered flax oil (500 mg/kg body weight/D, p.o); group $\mathrm{V}$ : fish oil group $(n=6)$ : administered fish oil $(500 \mathrm{mg} / \mathrm{kg}$ body weight/D, p.o). After 15 days of treatment, animals were fasted overnight and blood was collected by retroorbital puncture. Animals were sacrificed after 30 days of treatment. Liver and kidney tissues were excised immediately, washed in saline, weighed, and stored in $10 \%$ neutral buffered formalin for histological analysis. Blood was collected and centrifuged at $2000 \mathrm{rpm}$ for $15 \mathrm{~min}$ to collect serum for biochemical estimations.

\section{Blood biochemistry}

Serum glucose, total cholesterol, triglyceride, high-density lipoprotein (HDL), low-density lipoprotein (LDL), serum glutamic oxaloacetic transaminase (SGOT), serum glutamic pyruvic transaminase (SGPT) and alkaline phosphatase (ALP), total bilirubin, creatinine, urea, albumin, and total protein were estimated using commercial kits (Coral Clinical Systems, Goa, India). Very low-density lipoprotein cholesterol (VLDL) was estimated by using the formula: (triglyceride/5).

\section{Quantitative real-time reverse transcription-polymerase chain reaction analysis}

PBMCs were isolated by density gradient centrifugation by layering the blood sample over Histopaque-1077 (Sigma-Aldrich, Inc., USA). RNA was isolated by TRIzol (Invitrogen Co., Carlsbad, CA, USA) method. Total RNA was quantified using NanoDrop (ND1000, USA). The quality of RNA was analyzed by agarose gel

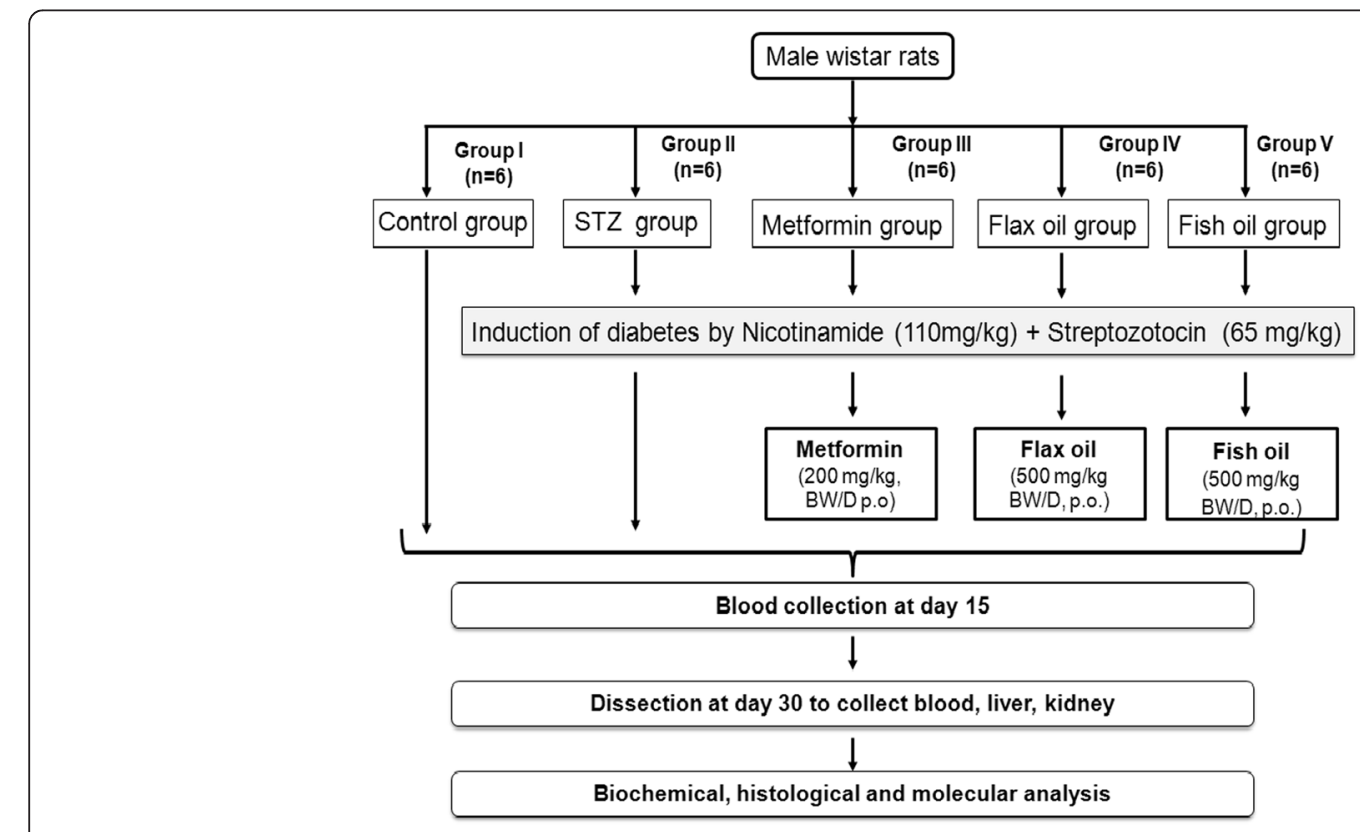

Fig. 1 Study design 
electrophoresis. Complementary DNA (cDNA) was prepared by using high-capacity cDNA Reverse Transcription kit (Applied Biosystems). Standard quantitative realtime transcription-polymerase chain reaction (qRT-PCR) was performed with the use of SYBR Green master mix (Applied Biosystems) for the following genes: PPAR $\gamma$, SREBP1, nuclear factor kappa $\beta$ (NFk $\beta)$, fatty acid synthase (FAS), long chain acyl CoA synthetases (ACSL), malonyl-CoA-acyl carrier protein transacylase (MCAT), tumor necrosis factor $\alpha(\mathrm{TNF} \alpha)$. KicqStart Primers (Sigma, USA) were used for gene expression studies and are listed in Table 1. qRT-PCR was performed using the Applied Biosystems 7300 Standard system. The reactions for each gene were performed in duplicate. Relative expression levels of genes were calculated and expressed as $2^{\Delta \mathrm{CT}}$ where $\Delta \mathrm{CT}$ is $C_{\mathrm{T}}(\mathrm{GAPDH})-C_{\mathrm{T}}(\operatorname{tar}-$ get gene) and this method is a modification of $2^{-\Delta \Delta C_{\mathrm{T}}}$ method (Gaines et al. 2010).

\section{Histological analysis}

Paraffin-embedded liver and kidney tissues were cut at $4 \mu \mathrm{m}$ and stained with hematoxylin and eosin. The slides were examined under a binocular microscope (Make: Olympus IX71) and photographed by using Image Pro Plus (v5.1.2.59).

Table 1 List of primers used for quantitative real-time PCR

\begin{tabular}{lll}
\hline Gene & Primer name & Sequence $\left(5^{\prime}-3^{\prime}\right)$ \\
\hline GAPDH & GAPDH F & AGTTCAACGGCACAGTCAAG \\
PPARY & GAPDH R & TACTCAGCACCAGCATCACC \\
& PPARY F & AAGACAACAGACAAATCACC \\
SREBP1 & SREBP F & CAGGGATATTITGGCATACTC \\
& SREBP R & AAACCTGAAGTGGTAGAAAC \\
NFKB & NFKB F & TATCCTCAAAGGCTGGG \\
& NFKB R & AAAAACGAGCCTAGAGATTG \\
FAS & FAS F & ACATCCTCTTCCTTGTCTTC \\
& FAS R & AAAAGGAAAGTAGAGTGTGC \\
ACSL & ACSL F & GACACATTCTGTTCACTACAG \\
& ACSL R & ACATTATGAACGATTGCTCC \\
MCAT & MCAT F & GCATTACACACTCTACAACG \\
& MCAT R & AAAACTCTAGGCTCAATCAAC \\
TNFa & TNFa F & GGATGTGTGTATTATGCCC \\
& TNFa R & CTCACACTCAGATCATCTC \\
& GAGAACCTGGGAGTAGATAAG
\end{tabular}

GAPDH glyceraldehyde-3-phosphate dehydrogenase, PPARY peroxisome proliferator-activated receptors $\gamma$, SREBP1 sterol regulatory element-binding protein 1, NFK $\beta$ nuclear factor kappa $\beta$, FAS fatty acid synthase, ACSL long chain acyl CoA synthetases, MCAT malonyl-CoA-acyl carrier protein transacylase, TNFa tumor necrosis factor a (Make: Sigma-Aldrich; $F$ forward primer sequence, $R$ reverse primer sequence)

\section{Statistical analysis}

Results are presented as mean \pm standard error (SE). All the statistical analyses were performed using SPSS PC+ package (Version 20, Chicago, IL, USA). The data were checked for normal distribution by testing for skewness. Skewed variables were transformed to normality using $\log$ to the base 10 transformation. Statistical differences between means in different groups were determined using one-way analysis of variance (ANOVA) test followed by post hoc Bonferonni multiple correction test. Mean values of various parameters from each group at D15 were compared with those at D30 using Student's $t$ test. $P \leq$ 0.05 was considered statistically significant.

\section{Results}

Food intake, body weights, and organ weights

The food intake of animals from the STZ group was higher at $\mathrm{D} 1(p<0.01), \mathrm{D} 15$, and $\mathrm{D} 30(p<0.05)$ as compared to that from the control. The body weights were lower at D15 $(p<0.05)$ and D30 $(p<0.01)$ when compared with those of the control (Table 2). Liver weights, hepatic index, and kidney weights were comparable while kidney index $(p<0.01)$ was higher in the STZ group as compared to that in the control (Table 2).

\section{Serum glucose levels}

Serum glucose levels were significantly higher $(p<0.01)$ in the STZ group than those in the control at D15 and D30 (Table 3).

\section{Comparison of glucose levels at D15 and D30 within the groups}

Glucose levels in the control, STZ, metformin, and flax oil groups were comparable at D15 and D30. However, glucose levels in the fish oil group were lower $(p<0.05)$ at D30 as compared to those at D15 (Table 5).

\section{Lipid profile}

At D15, the STZ group had higher serum cholesterol $(p<0.01)$, HDL, and LDL levels $(p<0.01)$ than the control group. A higher trend was observed for triglyceride and VLDL $(p=0.068)$ levels in the STZ group than for those in the control group. Animals from the metformin-treated group had lower cholesterol $(p<0.05)$, HDL, and LDL $(p<0.01)$ than those in the STZ group. The fish oil treatment group also lowered HDL and LDL levels $(P<0.05)$ than the STZ group (Table 3$)$.

At D30, higher serum cholesterol $(p<0.05)$, triglyceride, and VLDL levels $(p<0.01)$ were seen in the STZ group than in the control. Metformin group lowered cholesterol, triglyceride, and VLDL $(p<0.01)$ as compared to the STZ group. Flax oil treatment group lowered triglycerides and VLDL levels $(p<0.01)$ than the STZ group. Fish oil treatment group lowered cholesterol, 
Table 2 Food intake and body, liver, and kidney weights of animals

\begin{tabular}{|c|c|c|c|c|c|}
\hline & Control $(n=6)$ & $\operatorname{STZ}(n=6)$ & Metformin $(n=6)$ & Flax oil $(n=6)$ & Fish oil $(n=6)$ \\
\hline \multicolumn{6}{|l|}{ Food intake (g) } \\
\hline Day 1 & $14.66 \pm 3.58$ & $30.83 \pm 0.21^{* *}$ & $33.66 \pm 0.58$ & $31.83 \pm 2.69$ & $30.00 \pm 0.65$ \\
\hline Day 15 & $12.66 \pm 2.41$ & $23.33 \pm 2.07^{*}$ & $27.00 \pm 1.27$ & $28.33 \pm 1.80$ & $16.66 \pm 2.59$ \\
\hline Day 30 & $16.00 \pm 2.22$ & $26.50 \pm 3.55^{*}$ & $27.00 \pm 1.89$ & $33.66 \pm 0.45$ & $31.50 \pm 1.93$ \\
\hline \multicolumn{6}{|l|}{ Body weights (g) } \\
\hline Day 1 & $236.50 \pm 3.48$ & $235.50 \pm 8.54$ & $235.50 \pm 13.91$ & $245.83 \pm 3.84$ & $243.16 \pm 15.15$ \\
\hline Day 15 & $292.16 \pm 6.55$ & $232.33 \pm 20.28^{*}$ & $201.33 \pm 14.02$ & $231.83 \pm 12.68$ & $202.50 \pm 11.64$ \\
\hline Day 30 & $345.50 \pm 10.47$ & $223.33 \pm 30.34^{* *}$ & $176.50 \pm 14.93$ & $211.33 \pm 13.90$ & $198.33 \pm 11.47$ \\
\hline \multicolumn{6}{|c|}{ Liver and kidney weights } \\
\hline Liver weight (g) & $9.97 \pm 0.60$ & $7.68 \pm 0.59$ & $6.60 \pm 0.50$ & $7.60 \pm 0.51$ & $8.24 \pm 0.59$ \\
\hline Liver index (\%) & $2.87 \pm 0.12$ & $3.60 \pm 0.31$ & $3.78 \pm 0.19$ & $3.62 \pm 0.20$ & $4.17 \pm 0.24$ \\
\hline Kidney weight (g) & $1.60 \pm 0.13$ & $1.89 \pm 0.08$ & $1.76 \pm 0.12$ & $1.91 \pm 0.07$ & $1.84 \pm 0.03$ \\
\hline Kidney index (\%) & $0.46 \pm 0.03$ & $0.90 \pm 0.08^{* *}$ & $1.01 \pm 0.06$ & $0.91 \pm 0.04$ & $0.94 \pm 0.05$ \\
\hline
\end{tabular}

Data are presented as mean \pm SE

${ }^{*} p<0.05,{ }^{* *} p<0.01$ for comparison between the control and STZ group

triglyceride, and VLDL $(p<0.01)$ as compared to the STZ group (Table 3).

\section{Comparison of lipid profile parameters at D15 and D30 within the groups}

In the STZ group, serum HDL and LDL levels were lower $(p<0.01)$ at D30 as compared to those at D15. Serum cholesterol, triglyceride, and VLDL levels were lower $(p<0.01)$ at D30 as compared to those at D15 in the metformin group. In the flax and fish oil group, cholesterol, triglyceride, HDL, LDL, and VLDL levels were lower $(p<0.01)$ at D30 as compared to those at D15 (Table 5).

\section{Expression of genes involved in lipid metabolism}

The PPARy gene expression was lower in the STZ group $(p<0.05)$ as compared to that in the control. The treatment with metformin $(p<0.05)$ and fish oil $(p<0.01)$

Table 3 Serum glucose level and lipid profile at post treatment days 15 and 30

\begin{tabular}{|c|c|c|c|c|c|}
\hline & Control $(n=6)$ & $\mathrm{STZ}(n=6)$ & Metformin $(n=6)$ & Flax oil $(n=6)$ & Fish oil $(n=6)$ \\
\hline \multicolumn{6}{|l|}{ Glucose level (mg/dl) } \\
\hline At day 15 & $53.72 \pm 3.58$ & $294.11 \pm 14.85^{* *}$ & $340.98 \pm 30.14$ & $280.12 \pm 12.62$ & $315.36 \pm 10.66$ \\
\hline At day 30 & $54.11 \pm 4.89$ & $309.65 \pm 33.54^{* *}$ & $300.64 \pm 6.75$ & $315.18 \pm 16.20$ & $269.23 \pm 16.96$ \\
\hline \multicolumn{6}{|l|}{ Lipid profile } \\
\hline \multicolumn{6}{|l|}{ Post treatment day 15} \\
\hline Cholesterol (mg/dl) & $43.37 \pm 3.76$ & $98.24 \pm 12.83^{* *}$ & $58.79 \pm 4.47^{\#}$ & $87.31 \pm 9.03$ & $69.44 \pm 3.16$ \\
\hline Triglyceride (mg/dl) & $72.74 \pm 6.15$ & $171.96 \pm 39.49$ & $145.58 \pm 20.68$ & $114.01 \pm 15.45$ & $133.95 \pm 23.67$ \\
\hline $\mathrm{HDL}(\mathrm{mg} / \mathrm{dl})$ & $10.03 \pm 0.83$ & $22.10 \pm 2.11^{* *}$ & $8.09 \pm 1.55^{\# \#}$ & $22.93 \pm 1.95$ & $13.80 \pm 1.17^{\#}$ \\
\hline LDL (mg/dl) & $17.31 \pm 1.44$ & $38.12 \pm 3.65^{* *}$ & $13.96 \pm 2.68^{\# \#}$ & $39.56 \pm 3.37$ & $23.82 \pm 2.20^{\#}$ \\
\hline VLDL (mg/dl) & $14.54 \pm 1.23$ & $34.39 \pm 7.89$ & $29.19 \pm 4.13$ & $22.80 \pm 3.09$ & $26.79 \pm 4.73$ \\
\hline \multicolumn{6}{|l|}{ Post treatment day 30} \\
\hline Cholesterol (mg/dl) & $44.44 \pm 2.04$ & $68.22 \pm 10.04^{*}$ & $34.35 \pm 4.71^{\# \#}$ & $49.25 \pm 2.82$ & $34.62 \pm 4.75^{\# \#}$ \\
\hline Triglyceride (mg/dl) & $66.29 \pm 5.96$ & $201.33 \pm 31.23^{* *}$ & $43.14 \pm 8.12^{\# \#}$ & $44.81 \pm 11.19^{\# \#}$ & $42.03 \pm 9.13^{\# \#}$ \\
\hline $\mathrm{HDL}(\mathrm{mg} / \mathrm{dl})$ & $10.71 \pm 0.70$ & $9.95 \pm 1.10$ & $7.97 \pm 1.02$ & $13.05 \pm 1.06$ & $8.73 \pm 0.71$ \\
\hline LDL (mg/dl) & $18.48 \pm 1.21$ & $17.16 \pm 1.90$ & $13.75 \pm 1.77$ & $22.52 \pm 1.83$ & $15.05 \pm 1.23$ \\
\hline VLDL (mg/dl) & $13.25 \pm 1.19$ & $40.26 \pm 6.24^{* *}$ & $8.62 \pm 1.62^{\# \#}$ & $8.96 \pm 2.23^{\# \#}$ & $8.40 \pm 1.82^{\# \#}$ \\
\hline
\end{tabular}

Data are presented as mean $\pm \mathrm{SE}$

$H D L$ high-density lipoprotein cholesterol, $L D L$ low-density lipoprotein cholesterol, VLDL very low-density lipoprotein cholesterol

${ }^{*} p<0.05,{ }^{* *} p<0.01$ for comparison between the control and STZ group and ${ }^{\#} p<0.05,{ }^{\# \#} p<0.01$ for comparison between the STZ group and treatment groups 

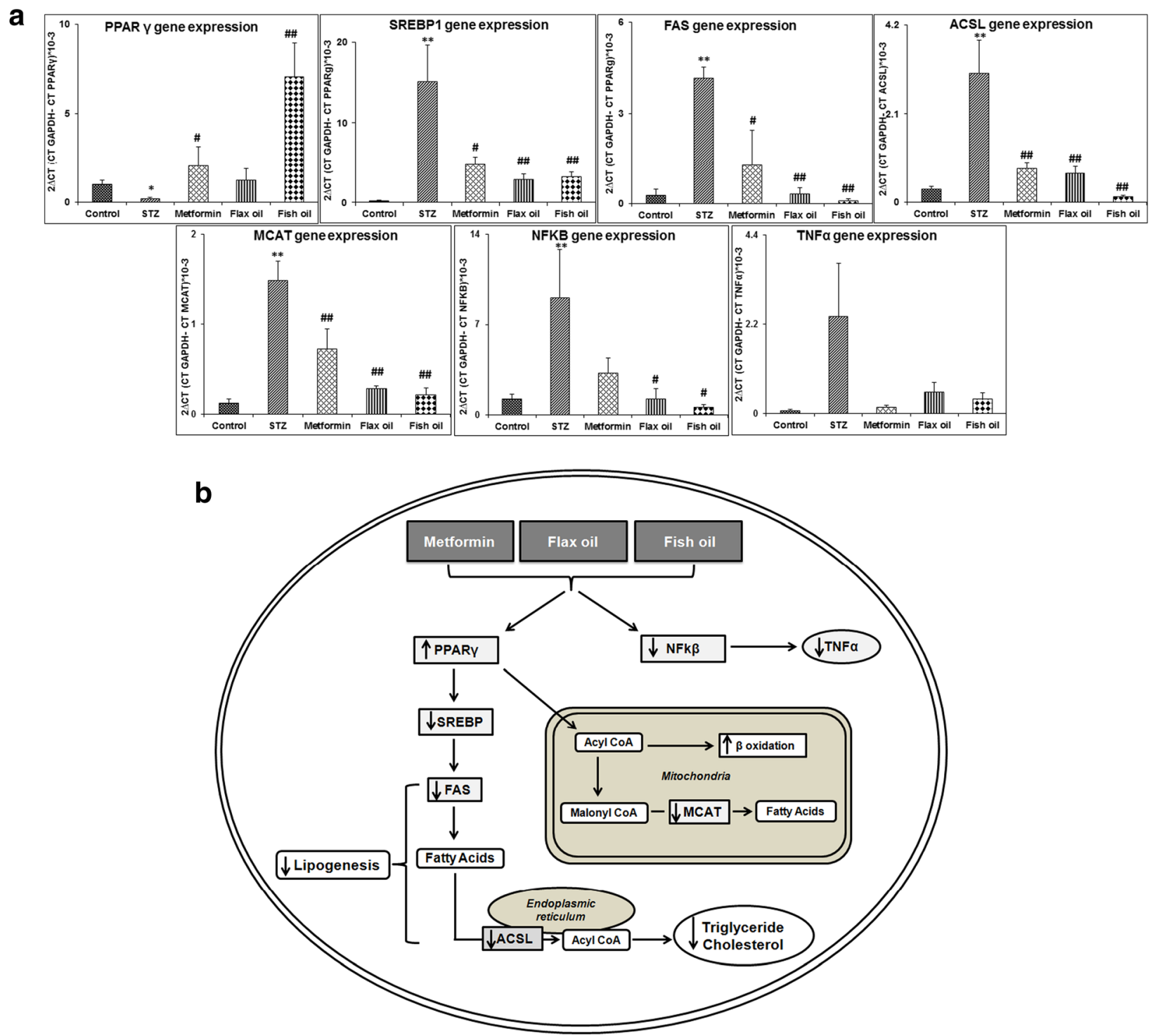

Fig. 2 a Expression of genes involved in lipid metabolism and inflammation. Data are presented as mean \pm SE. ${ }^{*} p<0.05$, ${ }^{* *} p<0.01$ for comparison between the control and STZ group and ${ }^{\#} p<0.05,{ }^{\# \#} p<0.01$ for comparison between the STZ group and treatment groups. GAPDH glyceraldehyde-3phosphate dehydrogenase, PPARY peroxisome proliferator-activated receptors $\gamma$, SREBP1 sterol regulatory element-binding protein, $N F K \beta$ nuclear factor kappa $\beta$, FAS fatty acid synthase, ACSL long chain acyl CoA synthetases, MCAT malonyl-CoA-acyl carrier protein transacylase, TNFa tumor necrosis factor a. $\mathbf{b}$ Diagrammatic representation of the possible mechanism of metformin and flax and fish oil on the lipid metabolism and inflammatory cytokines. PPARY peroxisome proliferator-activated receptors $\gamma$, SREBP sterol regulatory element-binding protein, NFK $\beta$ nuclear factor kappa $\beta, F A S$ fatty acid synthase, ACSL long chain acyl CoA synthetases, MCAT malonyl-CoA-acyl carrier protein transacylase, TNFa tumor necrosis factor a, up arrow up-regulation, down arrow down-regulation

increased PPAR $\gamma$ expression as compared to that in the STZ group (Fig. 2a).

The SREBP1 gene expression was higher in the STZ group $(p<0.01)$ as compared to that in the control while treatment with metformin $(p<0.05)$ and flax and fish oil lowered $(p<0.01)$ the expression as compared to that in the STZ group (Fig. 2a).

The expression of fatty acid synthase (FAS) was higher in the STZ group $(p<0.01)$ as compared to that in the control whereas the expression was lower in metformin $(p<0.05)$ and flax and fish oil groups $(p<0.01)$ when compared to that in the STZ group (Fig. 2a).

The ACSL gene expression was higher in the STZ group $(p<0.01)$ as compared to that in the control. Metformin and flax and fish oil $(p<0.01)$ lowered the expression of ACSL as compared to that in the STZ group (Fig. 2a).

The MCAT gene expression was higher in the STZ group $(p<0.01)$ as compared to that in the control. Metformin and flax and fish oil $(p<0.01)$ lowered the expression as compared to that in the STZ group (Fig. 2a). 


\section{Expression of genes involved in inflammation}

The NFk $\beta$ gene expression was higher in the STZ group $(p<0.05)$ as compared to that in the control. The metformin group did not show any significant difference as compared to the STZ group. Flax and fish oil $(p<0.05)$ lowered the expression as compared to that in the STZ group (Fig. 2a).

The TNF $\alpha$ gene expression did not show a significant difference although it was higher in the STZ group than in the control $(p=0.123)$. Metformin $(p=0.155)$ and flax $(p=0.404)$ and fish $(p=0.260)$ oil groups exhibited decreased expression of TNF $\alpha$ as compared to the STZ group, but the decrease was not statistically significant (Fig. 2a).

\section{Liver function test markers}

At D15, serum SGPT and ALP levels were higher $(p<0.05)$ in the STZ group than in the control, but SGOT and bilirubin levels were comparable to those in the control (Table 4).

At D30, serum ALP levels were higher $(p<0.01)$ in the STZ group as compared to those in the control. Metformin and flax and fish oil did not affect liver function test markers at D15 and D30 (Table 4).

\section{Comparison of liver function test markers between D15 and D30 within the groups}

In the control group, serum SGPT and ALP levels were lower $(p<0.05)$ at D15 as compared to those at D30. There was no difference in the liver function test markers in STZ and metformin groups. In both flax oil and fish oil groups, ALP levels were lower $(p<0.05)$ at D30 as compared to those at D15 (Table 5).

\section{Liver histology}

In the STZ-induced diabetic group, we observed some areas with pathological calcification in the partial triad focal hemorrhages and destruction of some bile ducts. It also showed destruction of hepatocytes, loss of hepatic lobules, and conjunction of the central vein. Surprisingly, the metformin group displayed destruction of some hepatocytes and congestion of the central vein. The flax and fish oil group displayed near-normal liver histology without any histological detectable anomalies (Fig. 3a).

\section{Renal function test markers}

At D15, serum urea $(p<0.01)$ levels were higher in the STZ group as compared to those in the control.

Table 4 Liver and renal function test markers at post treatment days 15 and 30

\begin{tabular}{|c|c|c|c|c|c|}
\hline & Control $(n=6)$ & $\mathrm{STZ}(n=6)$ & Metformin $(n=6)$ & Flax oil $(n=6)$ & Fish oil $(n=6)$ \\
\hline \multicolumn{6}{|l|}{ Liver function test markers } \\
\hline \multicolumn{6}{|l|}{ Post treatment day 15} \\
\hline SGOT (U/ml) & $104.10 \pm 3.97$ & $123.46 \pm 6.98$ & $162.11 \pm 20.38$ & $133.84 \pm 13.60$ & $116.79 \pm 8.20$ \\
\hline SGPT (U/ml) & $113.08 \pm 5.56$ & $167.50 \pm 15.28^{*}$ & $199.83 \pm 20.03$ & $202.16 \pm 7.52$ & $220.08 \pm 12.47$ \\
\hline ALP (KA Unit) & $28.15 \pm 4.06$ & $113.46 \pm 33.45^{*}$ & $103.88 \pm 15.53$ & $91.22 \pm 11.19$ & $98.98 \pm 4.34$ \\
\hline Bilirubin (mg/dl) & $0.08 \pm 0.18$ & $0.11 \pm 0.02$ & $0.12 \pm 0.04$ & $0.09 \pm 0.01$ & $0.10 \pm 0.01$ \\
\hline \multicolumn{6}{|l|}{ Post treatment day 30} \\
\hline SGOT (U/ml) & $113.71 \pm 9.81$ & $124.00 \pm 8.45$ & $134.48 \pm 9.27$ & $120.38 \pm 10.69$ & $136.15 \pm 6.41$ \\
\hline SGPT (U/ml) & $87.50 \pm 9.10$ & $134.80 \pm 24.83$ & $160.33 \pm 32.84$ & $150.00 \pm 34.53$ & $198.50 \pm 22.43$ \\
\hline ALP (KA Unit) & $15.78 \pm 1.59$ & $75.34 \pm 6.49^{* *}$ & $69.63 \pm 9.41$ & $53.80 \pm 5.78$ & $58.29 \pm 10.88$ \\
\hline Bilirubin (mg/dl) & $0.08 \pm 0.01$ & $0.11 \pm 0.03$ & $0.14 \pm 0.01$ & $0.06 \pm 0.02$ & $0.06 \pm 0.02$ \\
\hline \multicolumn{6}{|l|}{ Renal function test markers } \\
\hline \multicolumn{6}{|l|}{ Post treatment day 15} \\
\hline Creatinine (mg/dl) & $1.44 \pm 0.27$ & $2.38 \pm 0.23$ & $1.86 \pm 0.17$ & $1.49 \pm 0.27$ & $1.50 \pm 0.28$ \\
\hline Urea (mg/dl) & $38.37 \pm 3.37$ & $56.11 \pm 3.57^{* *}$ & $56.88 \pm 4.24$ & $46.95 \pm 2.26$ & $46.33 \pm 3.12$ \\
\hline Albumin (g/dl) & $2.19 \pm 0.15$ & $1.83 \pm 0.23$ & $1.61 \pm 0.26$ & $1.88 \pm 0.11$ & $2.15 \pm 0.19$ \\
\hline Total protein (g/dl) & $4.00 \pm 0.18$ & $3.68 \pm 0.29$ & $3.86 \pm 0.68$ & $3.80 \pm 0.25$ & $4.07 \pm 0.20$ \\
\hline \multicolumn{6}{|l|}{ Post treatment day 30} \\
\hline Creatinine (mg/dl) & $1.28 \pm 0.15$ & $1.69 \pm 0.30$ & $1.61 \pm 0.33$ & $1.33 \pm 0.10$ & $1.22 \pm 0.34$ \\
\hline Urea (mg/dl) & $40.52 \pm 4.50$ & $49.38 \pm 3.48$ & $50.88 \pm 2.29$ & $60.57 \pm 2.35$ & $51.22 \pm 4.80$ \\
\hline Albumin (g/dl) & $2.09 \pm 0.14$ & $1.70 \pm 0.17$ & $1.54 \pm 0.10$ & $1.68 \pm 0.11$ & $1.80 \pm 0.20$ \\
\hline Total protein (g/dl) & $3.71 \pm 0.09$ & $3.42 \pm 0.81$ & $3.08 \pm 0.19$ & $3.31 \pm 0.14$ & $3.23 \pm 0.12$ \\
\hline
\end{tabular}

Data are presented as mean \pm SE

SGOT serum glutamic oxaloacetic transaminase, SGPT serum glutamic pyruvic transaminase, ALP alkaline phosphatase

${ }^{*} p<0.05,{ }^{* *} p<0.01$ for comparison between the control and STZ group 
Table 5 Comparison of biochemical markers between post treatment days 15 and 30 within the groups

\begin{tabular}{|c|c|c|c|c|c|c|c|c|c|c|c|c|c|c|}
\hline & \multirow[t]{2}{*}{ Glucose } & \multicolumn{5}{|l|}{ Lipid profile } & \multicolumn{4}{|c|}{ Liver function test markers } & \multicolumn{4}{|c|}{ Renal function test markers } \\
\hline & & Cholesterol & Triglyceride & $\mathrm{HDL}$ & LDL & VLDL & SGOT & SGPT & ALP & Bilirubin & Creatinine & Urea & Albumin & Total protein \\
\hline \multicolumn{15}{|l|}{$p$ value } \\
\hline Control & 0.951 & 0.833 & 0.469 & 0.550 & 0.550 & 0.469 & 0.395 & 0.037 & 0.017 & 1.000 & 0.612 & 0.709 & 0.638 & 0.192 \\
\hline STZ & 0.662 & 0.108 & 0.585 & 0.001 & 0.001 & 0.586 & 0.961 & 0.274 & 0.310 & 0.966 & 0.103 & 0.215 & 0.673 & 0.453 \\
\hline Metformin & 0.243 & 0.004 & 0.001 & 0.950 & 0.950 & 0.001 & 0.245 & 0.333 & 0.088 & 0.667 & 0.522 & 0.242 & 0.813 & 0.301 \\
\hline Flax oil & 0.118 & 0.007 & 0.005 & 0.001 & 0.001 & 0.005 & 0.454 & 0.170 & 0.014 & 0.425 & 0.600 & 0.001 & 0.272 & 0.123 \\
\hline Fish oil & 0.044 & 0.000 & 0.005 & 0.004 & 0.004 & 0.005 & 0.092 & 0.425 & 0.011 & 0.186 & 0.547 & 0.413 & 0.233 & 0.004 \\
\hline
\end{tabular}

HDL high-density lipoprotein cholesterol, LDL low-density lipoprotein cholesterol, VLDL very low-density lipoprotein cholesterol, SGOT serum glutamic oxaloacetic transaminase, SGPT serum glutamic pyruvic transaminase, ALP alkaline phosphatase. The $p$ values in italics indicate significant differences in the biochemical markers, within the groups, between post treatment days 15 and 30

However, metformin and flax and fish oil did not show significant differences in renal function test markers at D15 and D30 (Table 4).

\section{Comparison of renal function test markers at D15 and D30 within the groups}

There was no difference in the renal function test markers in the control, STZ, and metformin groups. The urea levels were higher $(p<0.01)$ in the flax oil group while total protein levels were lower $(p<0.05)$ in the fish oil group at D30 as compared to those at D15 (Table 5).

\section{Kidney histology}

STZ group displayed blood vesicle conjunction, vacuolation of tubular epithelial cells, conjunction of glomerular capillary, cloudy change in many tubular cells, and some degeneration of the glomerulus. The metformin group displayed vacuolation of some tubular epithelial cells and conjunction of glomerular capillary. The flax oil and fish oil groups exhibited near-normal architecture and displayed significant recovery of the damage as compared to the STZ group (Fig. 3b).

\section{Discussion}

The general characteristics of STZ-treated diabetic rats include low body weights and elevated blood glucose (Howarth et al. 2005). We observed a significant decrease in body weights and sustained hyperglycemia in nicotinamide-STZ-treated rats indicating successful induction of diabetes. In the present study, both metformin and omega-3 fatty acids could not normalize the glucose levels at D15 which remained higher till D30 of treatment. However, fish oil treatment lowered the glucose levels at D30 as compared to those at D15. It has been reported that metformin alone may not adequately control hyperglycemia (Salama et al. 2013) and omega-3 fatty acids do not directly affect glucose homeostasis (Woodman et al. 2002). However, several studies have reported hypoglycemic- and insulin-sensitizing effects of metformin (Maheshwari et al. 2014; Mohammadi et al. 2012; Erejuwa et al. 2011) and omega-3 fatty acids (Jangale et al. 2013) in the STZ-nicotinamide-induced diabetic rats. Consistent with our findings, metformin treatment at a dose $500 \mathrm{mg} / \mathrm{kg}$ for 8 weeks was not able to lower blood glucose in diabetic rats (Alhaider et al. 2011). These differences are probably due to variations in the duration of treatment or dose of metformin/ omega-3 fatty acids which needs further investigation.

\section{Effect of n-3 PUFA intervention on lipid profile}

Several reports have documented significant lipid abnormalities, like elevated cholesterol, triglyceride, LDL, and VLDL in diabetic rats (Nasrolahi et al. 2012). We observed increase in the serum cholesterol, triglyceride, and VLDL levels in the STZ group indicating adverse effects of elevated glucose on lipid profile. However, longterm metformin treatment for 30 days reduced these levels. The beneficial lipid-lowering effects of metformin have been reported in diabetic rats (Nasrolahi et al. 2012). We have recently reported that long-term use of oral hypoglycemic agents significantly reduce triglyceride levels in diabetic men and LDL and HDL levels in diabetic women (Ghadge et al. 2014).

In the present study, flax oil and fish oil intervention normalized all lipid profile parameters at D30 as compared to those at D15. Several studies have reported triglyceride-lowering effects of dietary fish oil (Bremer et al. 2014; Hartweg et al. 2008) which have been primarily attributed to EPA and DHA (Skulas-Ray et al. 2011; Egert et al. 2009). The present study indicated activation of PPAR and modulation of SREBP1 in the animals treated with n-3 PUFA which are known to be the main mechanisms for a lipid-normalizing action of omega-3 fatty acids (Devarshi et al. 2013).

\section{Modulation of lipid metabolism genes by $n-3$ PUFA intervention}

In the present study, STZ induction markedly reduced the expression of PPAR and increased SREBP1 expression 

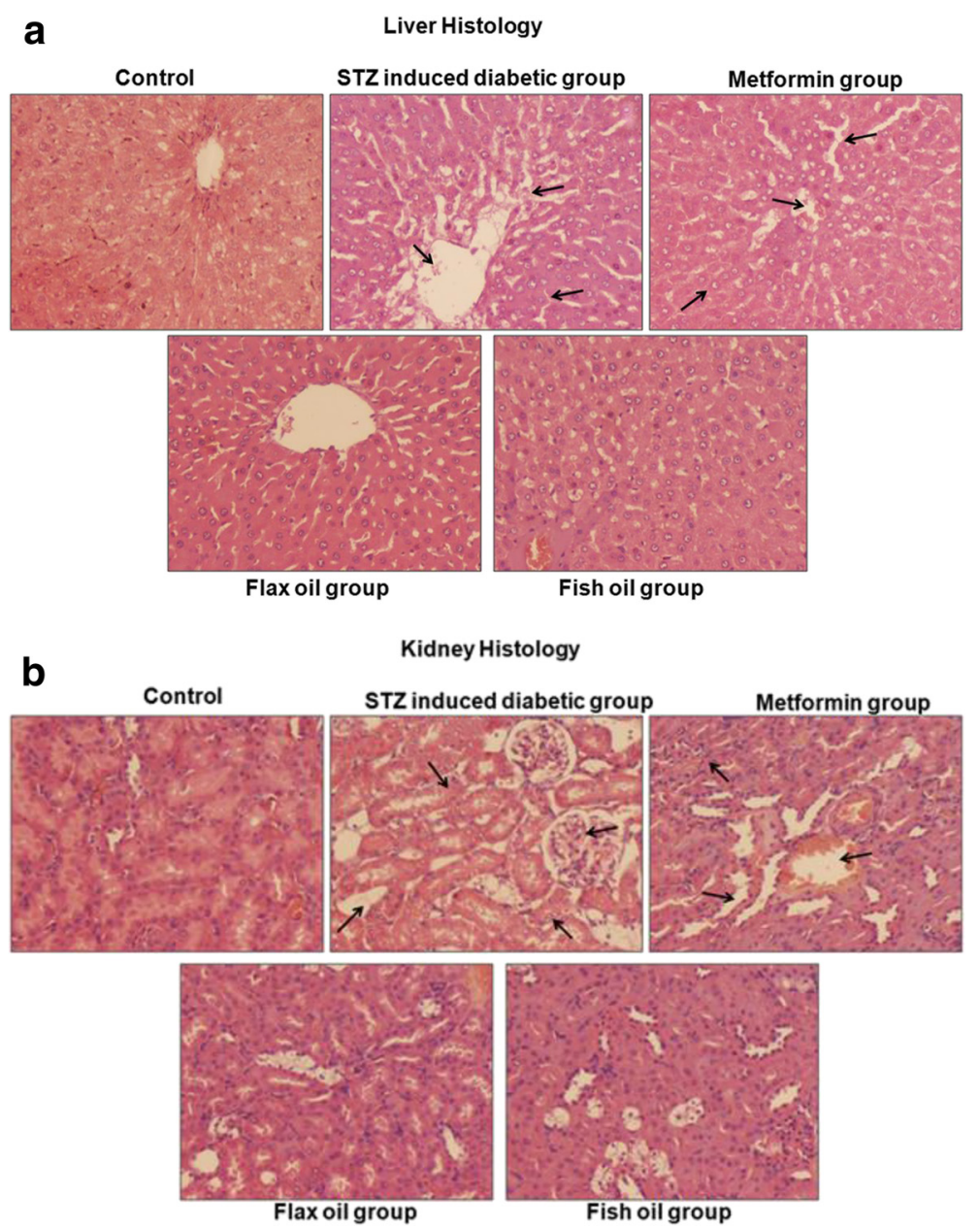

Fig. 3 a Liver histology of control, STZ-induced diabetic, metformin-treated, and flax/fish oil-treated animals. Hematoxylin and eosin-stained cross sections of paraffin-embedded liver tissues of rats from the control and experimental groups ( $\times 40)$. Liver from the control group shows normal architecture. Sections of the liver from the STZ-induced diabetic group show severe destruction of hepatic cells, pathological calcification, hemorrhages, and mild mononuclear cells in the portal tracts. Liver from the metformin-treated group shows some destructive changes and congestion of some central vein. The liver histology of animals treated with flax oil and fish oil shows completely normal liver architecture without any anatomically detectable anomalies. b Kidney histology of healthy, STZ-induced diabetic, metformin-treated, and flax/fish oil-treated animals. Hematoxylin and eosin-stained cross sections of paraffin-embedded kidney tissues of rats from the control and experimental groups ( $\times 40)$. Kidney from the control group shows normal kidney architecture. Sections of kidney from the STZ diabetic group showed conjunction of glomerular capillary and blood vesicle. Some tubular epithelial cells show vacuolation and cloudy changes. Kidney from the metformin-treated group shows vacuolation of some tubular epithelial cells and conjunction of glomerular capillary. The liver histology of animals treated with flax and fish oil shows no considerable changes and show normal architecture

which was restored by metformin as well as by fish oil (Fig. 2b). Metformin treatment is known to regulate incretin receptor axis via PPAR-dependent pathway in mice (Maida et al. 2011) and reduce SREBP expression by regulating AMP-activated protein kinase activity in rats (Zhou et al. 2001). Metformin has been shown to reduce fat content by decreasing the expression of SREBP1 and FAS (involved in fatty acid synthesis) in rat kidneys (Wang et al. 2006). A recent study reports reduction in PPAR expression and increase in SREBP expression in diabetic rats which was restored by dietary fish and flax oil supplementation (Devarshi et al. 2013). n-3 PUFA and their metabolites act as natural ligands for PPAR, promoting fatty acid oxidation and suppressing the transcription of lipogenic genes like FAS (Teran-Garcia et al. 2007).

ACSL, catalyzing the thioesterification of fatty acids, is a target of PPAR and is implicated in the pathogenesis of diabetes (Phillips et al. 2010). Recent report suggests that ACSL plays an important role in triglyceride synthesis (Yan et al. 2015). In the present study, STZ-treated animals showed significantly higher ACSL expression with high triglyceride levels. However, metformin and flax and fish oil interventions lowered the expression and consequently had significantly lower triglyceride 
levels. Metformin has been shown to lower ACSL expression and triglyceride levels in diabetic rats (Forcheron et al. 2009). Besides triglyceride synthesis by ACSL, MCAT, a mitochondrial protein, catalyzes transfer of CoA moiety to free thiol group on the acyl carrier protein in mitochondria, indicating its role in mitochondrial fatty acid synthesis (Zhang et al. 2003). Lower expression of MCAT along with ACSL has beneficial effects in normalizing the fatty acid and triglyceride levels ( $\mathrm{Li}$ et al. 2009; Zhang et al. 2003). In the present study also, metformin and flax and fish oil showed reduced MCAT expression indicating lower fatty acid synthesis and normal lipid profile (Fig. 2b).

\section{Modulation of inflammatory cytokine genes by n-3 PUFA intervention}

T2DM is a chronic inflammatory disease where transcription factor NFk $\beta$ activates the transcription of inflammatory cytokines like TNF $\alpha$ increasing the risk of secondary complications owing to their pro-atherogenic nature (JagannathanBogdan et al. 2011). In the present study, NFk $\beta$ expression was higher in the STZ group which was significantly lowered by flax and fish oil (Fig. 2b). However, TNFa expression was not significantly altered in the STZ group and treatment groups. Hyperglycemia-induced NFk $\beta$ activation in ex vivo isolated PBMCs has been reported in type 1 diabetic patients (Hofmann et al. 1998). Metformin administration has also been shown to downregulate the expression of $N F k \beta$ and TNF $\alpha$ and ameliorate $\beta$-cell dysfunction (Liu et al. 2014) in diabetes. Recent review highlights the role of n-3 PUFA in reducing TNFo expression (Ellulu et al. 2015).

\section{Effect of $n-3$ PUFA intervention on liver function test markers}

In the present study, SGPT and ALP levels were higher in the STZ group at D15 while ALP remained higher at D30 as compared to that in the control group. There are reports indicating hepatic dysfunction due to higher levels of liver enzymes such as SGPT, SGOT, and ALP in STZinduced diabetic rats (Sajitha et al. 2012). We have recently reported higher serum SGPT and bilirubin levels in diabetic male subjects and SGPT levels in diabetic female subjects (Ghadge et al. 2015). The biochemical alterations in the hepatic function markers observed in the present study were also associated with destructive changes in hepatocytes and accumulation of lipid droplets.

In this study, metformin treatment did not affect other markers. In contrast, a study in diabetic rats treated with metformin is reported to have elevated bilirubin levels (Nasrolahi et al. 2012). Liver section analysis of these animals displayed destruction of some hepatocytes and congestion of the central vein. A recent study reported mild granular degeneration, mild swelling (narrow sinusoidal capillaries), and normal hepatic architecture in the metformin-treated diabetic rats (Motshakeri et al. 2014). Some case report studies also demonstrated that metformin induces hepatotoxicity in diabetic subjects raising concern about its efficacy and safety profile (MirallesLinares et al. 2012; Cone et al. 2010).

Hepatoprotective effects of n-3 PUFA in chemically induced hepatotoxicity have been reported earlier from our laboratory (Chavan et al. 2013). In the present study, flax and fish oil intervention showed progressive effects in lowering ALP levels at D30 as compared to D15. Additionally, both of these groups exhibited normal hepatic architecture and displayed significant recovery of destructive changes.

\section{Effect of $n-3$ PUFA on renal function test markers}

Serum urea levels were higher in the STZ group at D15 as compared to those in the control group. Although renal function test markers at D30 were comparable to those of the control group, STZ induction still affected kidney histology and are consistent with other reports (Ahmed et al. 2014; Zafar et al. 2009). The metformin group showed no significant changes in the renal function test markers against the STZ group. However, we observed vacuolation of tubular epithelial cells in some tubules and conjunction of glomerular capillary in metformin-treated group. Similar findings like moderate cellular hydropic degeneration, atrophied renal corpuscle, and mild congestion of glomerular capillaries were reported in metformin-treated diabetic rats (Motshakeri et al. 2014). Further, in the present study, fish oil treatment progressively lowered total protein levels at D30 as compared to those at D15. Flax and fish oil also showed normal kidney histology. Similarly, dietary flax and fish oil have shown to improve renal abnormalities in rats (Hassan et al. 2015; Velasquez et al. 2003).

\section{Conclusion}

In conclusion, the treatment with metformin and flax/fish oil intervention in diabetic rats improves serum lipid profile and the expression of transcription factors modulating lipid metabolism such as PPAR- $\gamma$ and SREBP1 and lowers atherogenic cytokine like NFk $\beta$. In the present study, flax oil and/or fish oil exhibited hepatoprotective and nephroprotective effects under uncontrolled hyperglycemic states. The combination therapy of metformin and n-3 PUFA intervention is worth investigating in T2DM subjects.

\footnotetext{
Competing interests

The authors have no conflict of interest in connection with the contents of this article.

\section{Authors' contributions}

AG performed the experiments, analyzed the data and wrote the manuscript. $\mathrm{AH}$ participated in the design and coordination of the study. MK performed histological examinations of the tissue sections and analyzed the histological differences among the study groups. VP participated in the design and coordination of the study. AK conceived, designed and coordinated the study, analyzed the data and wrote the manuscript. All authors read and approved the final manuscript.
} 


\section{Acknowledgements}

Authors are thankful to Bharati Vidyapeeth Deemed University for financial support. We gratefully acknowledge Dr. Yogesh Shouche, Microbial Culture Collection (MCC), National Center for Cell Science (NCCS), Pune, for providing the qRT-PCR facility. Authors are also thankful to Prof. Prabhakar Ranjekar, Ex-Director, Interactive Research School for Health Affairs (IRSHA), Bharati Vidyapeeth Deemed University, Pune, for his valuable suggestions.

\section{Compliance with ethics guidelines}

All institutional and national guidelines for the care and use of laboratory animals were followed. The study was carried out as per the CPCSEA (Committee for the Purpose of Control and Supervision of Experiments on Animals) guidelines after the approval of Institutional Animal Ethics Committee (Ref. No: BVDUMC/189/2014-2015).

\section{Author details}

${ }^{1}$ Nutrigenomics and Functional Foods Laboratory, Interactive Research School for Health Affairs (IRSHA), Bharati Vidyapeeth Deemed University, Pune-Satara Road, Pune, Maharashtra 411043, India. ${ }^{2}$ Department of Pathology, Bharati Vidyapeeth Medical College, Bharati Vidyapeeth Deemed University, Pune-Satara Road, Pune, Maharashtra 411043, India. ${ }^{3}$ Department of Pharmacology, Bharati Vidyapeeth Medical College, Bharati Vidyapeeth Deemed University, Pune-Satara Road, Pune, Maharashtra 411043, India.

\section{Received: 28 May 2015 Accepted: 11 December 2015}

\section{Published online: 17 March 2016}

\section{References}

Ahmed D, Kumar V, Verma A, Gupta PS, Kumar H, Dhingra V, Mishra V, Sharma M

(2014) Antidiabetic, renal/hepatic/pancreas/cardiac protective and antioxidant potential of methanol/dichloromethane extract of albizzia lebbeck benth. Stem bark (alex) on streptozotocin induced diabetic rats. BMC Complement Altern Med 14:243. doi:10.1186/1472-6882-14-243

Alhaider AA, Korashy HM, Sayed-Ahmed MM, Mobark M, Kfoury H, Mansour MA (2011) Metformin attenuates streptozotocin-induced diabetic nephropathy in rats through modulation of oxidative stress genes expression. Chem Biol Interact 192(3):233-242. doi:10.1016/j.cbi.2011.03.014

Ander BP, Dupasquier CMC, Prociuk MA, Pierce GN (2003) Polyunsaturated fatty acids and their effects on cardiovascular disease. Exp Clin Cardiol 8(4):164-172

Bremer AA, Stanhope KL, Graham JL, Cummings BP, Ampah SB, Saville BR, Havel PJ (2014) Fish oil supplementation ameliorates fructose-induced hyperTG mia and insulin resistance in adult male rhesus macaques. J Nutr 144(1):5-11. doi:10.3945/jn.113.178061

Brenna O, Qvigstad G, Brenna E, Waldum HL (2003) Cytotoxicity of streptozotocin on neuroendocrine cells of the pancreas and the gut. Dig Dis Sci 48(5):906-910. doi:10.1023/A:1023043411483

Calder PC (2007) Immunomodulation by omega-3 fatty acids. Prostaglandins Leukot Essent Fatty Acids 77(5-6):327-335. doi:10.1016/j.plefa.2007.10.015

Chavan T, Khadke S, Harke S, Ghadge A, Karandikar M, Pandit V, Ranjekar P, Kulkarni O, Kuvalekar A (2013) Hepatoprotective effect of polyunsaturated fatty acids against repeated subacute acetaminophen dosing in rats. Int $\rfloor$ Pharm Bio Sci 4(2):286-295

Cone CJ, Bachyrycz AM, Murata GH (2010) Hepatotoxicity associated with metformin therapy in treatment of type 2 diabetes mellitus with nonalcoholic fatty liver disease. Ann Pharmacother 44(10):1655-1659. doi:10.1345/aph.1P099

Connor WE (2000) Importance of n-3 fatty acids in health and disease. Am J Clin Nutr 71(1):171-175

Cummings BP, Stanhope KL, Graham JL, Griffen SC, Havel PJ (2010) Supplementation with EPA or fish oil for 11 months lowers circulating lipids, but does not delay the onset of diabetes in UC Davis-type 2 diabetes mellitus rats. Br J Nutr 104(11):1628-1634. doi:10.1017/S0007114510002655

Dessi M, Noce A, Bertucci P, di Villahermosa SM, Zenobi R, Castagnola V, Addessi E, Di Daniele N (2013) Atherosclerosis, dyslipidemia, and inflammation: the significant role of polyunsaturated fatty acids. ISRN Inflamm 2013:191823. doi:10.1155/2013/191823

Devarshi PP, Jangale NM, Ghule AE, Bodhankar SL, Harsulkar AM (2013) Beneficial effects of flaxseed oil and fish oil diet are through modulation of different hepatic genes involved in lipid metabolism in streptozotocin-nicotinamide induced diabetic rats. Genes Nutr 8(3):329-342. doi:10.1007/s12263-012-0326-2

Di Minno MN, Russolillo A, Lupoli R, Ambrosino P, Di Minno A, Tarantino G (2012) Omega-3 fatty acids for the treatment of non-alcoholic fatty liver disease. World J Gastroenterol 18(41):5839-5847. doi:10.3748/wjg.v18.i41.5839

Egert S, Kannenberg F, Somoza V, Erbersdobler HF, Wahrburg U (2009) Dietary alpha-linolenic acid, EPA, and DHA have differential effects on LDL fatty acid composition but similar effects on serum lipid profiles in normolipidemic humans. J Nutr 139(5):861-868. doi:10.3945/jn.108.103861

Ellulu MS, Khaza'ai H, Abed Y, Rahmat A, Ismail P, Ranneh Y (2015) Role of fish oil in human health and possible mechanism to reduce the inflammation. Inflammopharmacology 23(2-3):79-89. doi:10.1007/s10787-015-0228-1

Erejuwa OO, Sulaiman SA, Wahab MS, Sirajudeen KN, Salleh MS, Gurtu S (2011) Glibenclamide or metformin combined with honey improves glycemic control in streptozotocin-induced diabetic rats. Int J Biol Sci 7(2):244-252. doi:10.7150/ijbs.7.244

Erejuwa OO, Sulaiman SA, Wahab MS (2012) Honey- a novel antidiabetic agent. Int J Biol Sci 8(6):913-934. doi:10.7150/ijbs.3697

Forbes JM, Cooper ME (2013) Mechanisms of diabetic complications. Physiol Rev 93(1):137-188. doi:10.1152/physrev.00045.2011

Forcheron F, Basset A, Abdallah P, Del Carmine P, Gadot N, Beylot M (2009) Diabetic cardiomyopathy: effects of fenofibrate and metformin in an experimental model the Zucker diabetic rat. Cardiovasc Diabetol 8:16. doi:10.1186/1475-2840-8-16

Gaines TA, Zhang W, Wang D, Bukun B, Chisholm ST, Shaner DL, Nissen SJ, Patzoldt WL, Tranel PJ, Culpepper AS, Grey TL, Webster TM, Vencill WK, Sammons RD, Jiang J, Preston C, Leach JE, Westra P (2010) Gene amplification confers glyphosate resistance in Amaranthus palmeri. Proc Natl Acad Sci U S A 107(3):1029-1034. doi:10.1073/pnas.0906649107

Ghadge AA, Harke SM, Khadke SP, Diwan AG, Pankaj M, Kulkarni OP, Ranjekar PK, Kuvalekar AA (2014) Circulatory adipocytokines and lipid profile variations in type-2 diabetic subjects: desirable side-effects of antidiabetic drugs. Diabetes Metab Syndr 8(4):230-232. doi:10.1016/j.dsx.2014.09.010

Ghadge A, Harke S, Khadke S, Diwan A, Pankaj M, Kulkarni O, Ranjekar P, Harsulkar A, Kuvalekar AA (2015) Effects of commonly used antidiabetic drugs on antioxidant enzymes and liver function test markers in type 2 diabetes mellitus subjects-pilot study. Exp Clin Endocrinol Diabetes 123(8):500-507. doi:10.1055/s-0035-1554654

Hartweg J, Perera R, Montori V, Dinneen S, Neil HA, Farmer A (2008) Omega-3 polyunsaturated fatty acids (PUFA) for type 2 diabetes mellitus. Cochrane Database Syst Rev 1:Cd003205. doi:10.1002/14651858.CD003205

Hassan HA, Edrees GM, El-Gamel EM, El-Sayed EA (2015) Proanthocyanidin and fish oil potent activity against cisplatin-induced renal cell cycle arrest and apoptosis in rats. Ren Fail 37(8):1356-1362. doi:10.3109/ $0886022 X .2015 .1073528$

Hendrich S (2010) (n-3) fatty acids: clinical trials in people with type 2 diabetes. Adv Nutr 1(1):3-7. doi:10.3945/an.110.1003

Hofmann MA, Schiekofer S, Kanitz M, Klevesath MS, Joswig M, Lee V, Morcos M, Tritschler H, Ziegler R, Wahl P, Bierhaus A, Nawroth PP (1998) Insufficient glycemic control increases nuclear factor-kappa B binding activity in peripheral blood mononuclear cells isolated from patients with type 1 diabetes. Diabetes Care 21(8):1310-1316. doi:10.2337/diacare.21.8.1310

Howarth FC, Jacobson M, Shafiullah M, Adeghate E (2005) Long-term effects of streptozotocin-induced diabetes on the electrocardiogram, physical activity and body temperature in rats. Exp Physiol 90(6):827-835. doi:10.1113/ expphysiol.2005.031252

Jagannathan-Bogdan M, McDonnell ME, Shin H, Rehman Q, Hasturk H, Apovian CM, Nikolajczyk BS (2011) Elevated proinflammatory cytokine production by a skewed T cell compartment requires monocytes and promotes inflammation in type 2 diabetes. J Immunol 186(2):1162-1172. doi:10.4049/ jimmunol.1002615

Jangale NM, Devarshi PP, Dubal AA, Ghule AE, Koppikar SJ, Bodhankar SL, Chougale AD, Kulkarni MJ, Harsulkar AM (2013) Dietary flaxseed oil and fish oil modulates expression of antioxidant and inflammatory genes with alleviation of protein glycation status and inflammation in liver of streptozotocin-nicotinamide induced diabetic rats. Food Chem 141(1):187-195. doi:10.1016/j.foodchem.2013.03.001

King GL (2008) The role of inflammatory cytokines in diabetes and its complications. J Periodontol 79(8):1527-1534. doi:10.1902/jop.2008.080246

Konieczna J, Sanchez J, van Schothorst EM, Torrens JM, Bunschoten A, Palou M, Pico C, Keijer J, Palou A (2014) Identification of early transcriptome-based biomarkers related to lipid metabolism in peripheral blood mononuclear 
cells of rats nutritionally programmed for improved metabolic health. Genes Nutr 9(1):366. doi:10.1007/s12263-013-0366-2

Kooy A, de Jager J, Lehert P, Bets D, Wulffelé MG, Donker AJ, Stehouwer CD (2009) Long-term effects of metformin on metabolism and microvascular and macrovascular disease in patients with type 2 diabetes mellitus. Arch Intern Med 169(6):616-625. doi:10.1001/archinternmed.2009.20

Li LO, Ellis JM, Paich HA, Wang S, Gong N, Altshuller G, Thresher RJ, Koves TR, Watkins M, Muoio DM, Cline GW, Shulman Gl, Coleman RA (2009) Liverspecific loss of long chain acyl-CoA synthetase-1 decreases triacylglycerol synthesis and betaoxidation and alters phospholipid fatty acid composition. J Biol Chem 284(41):27816-27826. doi:10.1074/jbc.M109.022467

Li HT, Wu XD, Davey AK, Wang J (2011) Antihyperglycemic effects of baicalin on streptozotocin - nicotinamide induced diabetic rats. Phytother Res 25(2):189-194. doi:10.1002/ptr.3238

Liu J, Ma DWL (2014) The role of n-3 polyunsaturated fatty acids in the prevention and treatment of breast cancer. Nutrients 6(11):5184-5223. doi:10.3390/nu6115184

Liu SN, Liu Q, Sun SJ, Hou SC, Wang Y, Shen ZF (2014) Metformin ameliorates beta-cell dysfunction by regulating inflammation production, ion and hormone homeostasis of pancreas in diabetic KKAy mice. Yao Xue Xue Bao 49(11):1554-1562

Maheshwari RA, Balaraman R, Sen AK, Seth AK (2014) Effect of coenzyme Q10 alone and its combination with metformin on streptozotocin-nicotinamide-induced diabetic nephropathy in rats. Indian J Pharmacol 46(6):627-632. doi:10.4103/0253-7613.144924

Maida A, Lamont BJ, Cao X, Drucker DJ (2011) Metformin regulates the incretin receptor axis via a pathway dependent on peroxisome proliferator-activated receptor-alpha in mice. Diabetologia 54(2):339-349. doi:10.1007/s00125-010-1937-z

Miralles-Linares F, Puerta-Fernandez S, Bernal-Lopez MR, Tinahones FJ, Andrade RJ, Gomez-Huelgas R (2012) Metformin-induced hepatotoxicity. Diabetes Care 35, e21. doi:10.2337/dc11-2306

Mohammadi J, Delaviz H, Malekzadeh JM, Roozbehi A (2012) The effect of hydro alcoholic extract of Juglans regia leaves in streptozotocin-nicotinamide induced diabetic rats. Pak J Pharm Sci 25(2):407-411

Motshakeri M, Ebrahimi M, Goh YM, Othman HH, Hair-Bejo M, Mohamed S (2014) (2014) effects of brown seaweed (sargassum polycystum) extracts on kidney, liver, and pancreas of type 2 diabetic rat model. Evid Based Complement Alternat Med 2014:379407. doi:10.1155/2014/379407

Mozaffarian D, Wu JHY (2012) (n-3) fatty acids and cardiovascular health: are effects of EPA and DHA shared or complementary? J Nutr 142(3):614-625. doi:10.3945/in.111.149633

Nasrolahi O, Heidari R, Rahmani F, Farokhi F (2012) Effect of natural honey from Ilam and metformin for improving glycemic control in streptozotocin-induced diabetic rats. Avicenna J Phytomed 2(4):212-221

Nettleton JA, Katz R (2005) n-3 long-chain polyunsaturated fatty acids in type 2 diabetes: a review. J Am Diet Assoc 105(3):428-440. doi:10.1016/j.jada.2004.11.029

Ozder A (2014) Lipid profile abnormalities seen in t2dm patients in primary healthcare in turkey: a cross-sectional study. Lipids Health Dis 13:183. doi:10.1186/1476-511x-13-183

Pari L, Saravanan R (2007) Beneficial effect of succinic acid monoethyl ester on erythrocyte membrane bound enzymes and antioxidant status in streptozotocin-nicotinamide induced type 2 diabetes. Chem Biol Interact 169(1):15-24. doi:10.1016/j.cbi.2007.04.010

Phillips CM, Goumidi L, Bertrais S, Field MR, Cupples LA, Ordovas JM, Defoort C, Lovegrove JA, Drevon CA, Gibney MJ, Blaak EE, Kiec-Wilk B, Karlstrom B, Lopez-Miranda J, McManus R, Hercberg S, Lairon D, Planells R, Roche HM (2010) Gene-nutrient interactions with dietary fat modulate the association between genetic variation of the ACSL1 gene and metabolic syndrome. J Lipid Res 51(7):1793-1800. doi:10.1194/jlr.M003046

Prabhakar PK, Prasad R, Ali S, Doble M (2013) Synergistic interaction of ferulic acid with commercial hypoglycemic drugs in streptozotocin induced diabetic rats. Phytomedicine 20(6):488-494. doi:10.1016/j.phymed.2012

Rojas LB, Gomes MB (2013) Metformin: an old but still the best treatment for type 2 diabetes. Diabetol Metab Syndr 5(1):6. doi:10.1186/1758-5996-5-6

Saadi T, Waterman M, Yassin H, Baruch Y (2013) Metformin-induced mixed hepatocellular and cholestatic hepatic injury: case report and literature review. Int J Gen Med 6:703-706. doi:10.2147/JGM.S49657

Sajitha PC, Punitha D, Danya U, Udhayasankar MR, Baluprakash T, Arumugasamy K (2012) Antidiabetic activity of Anisochillus dysophylloides wall. ex Benth. (lamiaceae) in streptozotocin induced type II diabetes in male wistar albino rats. International Journal of Plant Animal and Environmental Sciences 2(4):40-43

Salama RM, Schaalan MF, Elkoussi AA, Khalifa AE (2013) Potential utility of sodium selenate as an adjunct to metformin in treating type II diabetes mellitus in rats: a perspective on protein tyrosine phosphatase. Biomed Res Int 2013:231378. doi:10.1155/2013/231378

Saravanan R, Pari L (2007) Succinic acid monoethyl ester, a novel insulinotropic agent: effect on lipid composition and lipid peroxidation in streptozotocin-nicotin-amide induced type 2 diabetic rats. Mol Cell Biochem 296(1-2):165-176. doi:10.1007/s11010-006-9312-6

Sharma AK, Sharma A, Kumari R, Kishore K, Sharma D, Srinivasan BP, Sharma A, Singh SK, Gaur S, Jatav VS, Sharma P, Srivastava V, Joshi S, Joshi M, Dhakad PK, Kanawat DS, Mishra A, Sharma A, Singh D, Singh RP, Chawda HS, Singh R, Raikwar SK, Kurmi MK, Khatri P, Agarwal A, Munajjam A (2012) Sitagliptin, sitagliptin and metformin, or sitagliptin and amitriptyline attenuate streptozotocin-nicotinamide induced diabetic neuropathy in rats. J Biomed Res 26(3):200-210. doi:10.7555/JBR.26.20110054

Skulas-Ray AC, Kris-Etherton PM, Harris WS, Vanden Heuvel JP, Wagner PR, West SG (2011) Dose response effects of omega-3 fatty acids on triglycerides, inflammation, and endothelial function in healthy persons with moderate hypertriglyceridemia. Am J Clin Nutr 93(2):243-252. doi:10.3945/ajcn.110.003871

Swanson D, Block R, Mousa SA (2012) Omega-3 fatty acids EPA and DHA: health benefits throughout life. Adv Nutr 3(1):1-7. doi:10.3945/an.111.000893

Szkudelski T (2012) Streptozotocin-nicotinamide-induced diabetes in the rat. Characteristics of the experimental model. Exp Biol Med (Maywood) 237(5):481-490. doi:10.1258/ebm.2012.011372

Teran-Garcia M, Adamson AW, Yu G, Rufo C, Suchankova G, Dreesen TD, Tekle M, Clarke SD, Gettys TW (2007) Polyunsaturated fatty acid suppression of fatty acid synthase (FASN): evidence for dietary modulation of NF-Y binding to the Fasn promoter by SREBP-1C. Biochem J 402(3):591-600. doi:10.1042/BJ20061722

Velasquez T, Bhathena SJ, Ranich T, Schwartz AM, Kardon DE, Ali AA, Haudenschild CC, Hansen CT (2003) Dietary flaxseed meal reduces proteinuria and ameliorates nephropathy in an animal model of type II diabetes mellitus. Kidney Int 64(6):2100-2107. doi:10.1046/j.1523-1755.2003.00329.x

Wang W, Guo XH, Wu HH, Wang NH, Xu XS (2006) Effect of fenofibrate and metformin on lipotoxicity in OLETF rat kidney. Beijing Da Xue Xue Bao 38(2):170-175

Wang C, Liu F, Yuan Y, Wu J, Wang H, Zhang L, Hu P, Li Z, Li Q, Ye J (2014) Metformin suppresses lipid accumulation in skeletal muscle by promoting fatty acid oxidation. Clin Lab 60(6):887-896

Woodman RJ, Mori TA, Burke V, Puddey IB, Watts GF, Beilin LJ (2002) Effects of purified eicosapentaenoic and docosahexaenoic acids on glycemic control, blood pressure, and serum lipids in type 2 diabetic patients with treated hypertension. Am J Clin Nutr 76(5):1007-1015

Wu JH, Micha R, Imamura F, Pan A, Biggs ML, Ajaz O, Djousse L, Hu FB, Mozaffarian D (2012) Omega-3 fatty acids and incident type 2 diabetes: a systematic review and meta-analysis. Br J Nutr 107(2):214-227. doi:10.1017/S0007114512001602

Yan S, Yang XF, Liu HL, Fu N, Ouyang Y, Qing K (2015) Long-chain acyl-CoA synthetase in fatty acid metabolism involved in liver and other diseases: an update. World J Gastroenterol 21(12):3492-3498. doi:10.3748/wjg.v21.i12.3492

Zafar M, Naqvi SN-u-H, Ahmed M, Kaimkhani ZA (2009) Altered kidney morphology and enzymes in streptozotocin induced diabetic rats. Int J Morphol 27(3):783-790

Zhang L, Joshi AK, Smith S (2003) Cloning, expression, characterization, and interaction of two components of a human mitochondrial fatty acid synthase. Malonyltransferase and acyl carrier protein. J Biol Chem 278(41):40067-40074. doi:10.1074/jbc.M306121200

Zheng J, Woo SL, Hu X, Botchlett R, Chen L, Huo Y, Wu C (2015) Metformin and metabolic diseases: a focus on hepatic aspects. Front Med. doi:10.1007/s1 1684-015-0384-0

Zhou G, Myers R, Li Y, Chen Y, Shen X, Fenyk-Melody J, Wu M, Ventre J, Doebber T, Fujii N, Musi N, Hirshman MF, Goodyear LJ, Moller DE (2001) Role of AMP-activated protein kinase in mechanism of metformin action. J Clin Invest 108(8):1167-1174. doi:10.1172/JCI13505 